\title{
El discurso de Protágoras sobre el bien en el Protágoras de Platón ${ }^{1}$
}

\section{Protagoras' Speech on the Good in Plato's Protagoras}

\author{
José Edgar GoNZÁLEZ VARELA \\ https://orcid.org/0000-0003-1491-1844 \\ Universidad Nacional Autónoma de México, México \\ joedgova@gmail.com
}

Resumen: El discurso de Protágoras sobre el bien en el Protágoras (334a3-c6) no ha sido correctamente interpretado. En general se asume que el sofista expone en éste un tipo de relativismo en torno al bien, el cual aparentemente no recibe una respuesta de Sócrates. En este trabajo defiendo una interpretación distinta, según la cual la posición filosófica que Protágoras expone en su discurso es pluralista. Asimismo, sostengo que Sócrates sí le contesta. La respuesta se encuentra en la elaboración que el filósofo hace de una tesis hedonista, la cual Protágoras termina aceptando. En efecto, dicho hedonismo es un monismo sobre el bien y, por tanto, es inconsistente con la posición pluralista protagórica previa. La moraleja de este intercambio es que el sofista no sabe lo que es el bien, el fin de la educación, pues es llevado a una posición inconsistente sobre el mismo.

Palabras Clave: educación, hedonismo, pluralismo, sofistas, virtud

AbSTRACT: Protagoras' discourse on the good in the Protagoras (334a3-c6) has not been correctly interpreted. In general, it is assumed that the sophist presents there a sort of relativism about the good, which does not receive any response by Socrates. In this paper I defend a different interpretation, according to which, the philosophical position that Protagoras introduces in the speech is a pluralist position. Moreover, I hold that Socrates does respond to the speech. This response is in Socrates' development of a hedonist thesis, which is subsequently accepted by Protagoras. Indeed, this sort of hedonism is a monism about the good and, therefore, is inconsistent with the previous Protagorean pluralist position. The moral of this exchange is, then, that the sophist does not know what the good is, the goal of education, for he is led to an inconsistent position about it.

\footnotetext{
${ }^{1}$ Agradezco los útiles comentarios a este trabajo de dos dictaminadores de NOVA TELLVS y el apoyo del proyecto PAPIIT IN403819 de la DGAPA. 
KeYwords: Education, Hedonism, Pluralism, Sophists, Virtue

ReCiBIDO: 13/04/2019 • ACEPTADO: 09/08/2019 • Versión FinAL: 18/12/2019

\section{INTRODUCCIÓN}

En el diálogo platónico Protágoras, el personaje homónimo pronuncia un breve discurso sobre el bien (Prt., 334a3-c6, ed. 1903). El sentido de dicho discurso y el papel que éste desempeña en el diálogo no han sido, a mi juicio, correctamente interpretados. Algunos han visto en éste una expresión del relativismo que parece atribuírsele al sofista en el Teeteto (Tht., 152a2-4, ed. 1995). Otros han negado enfáticamente que tal relativismo se manifieste en este discurso, pero no han ofrecido una explicación convincente de qué posición expresa entonces, ni cuál es su función dramática. Wilburn 2016, por su parte, ha argumentado que el objetivo principal del discurso es suscitar dudas sobre la comprensión que Protágoras tiene en torno al bien y preparar el terreno para luego sugerir que el sofista de Abdera está comprometido con el hedonismo que se discute en la parte posterior del diálogo que lleva su nombre. De este modo, Platón genera dudas acerca de la aptitud de Protágoras como maestro de sabiduría. Sin embargo, Wilburn no explica correctamente la posición errónea que Platón le atribuye al sofista, ni la relación entre dicha postura y el hedonismo que éste termina aceptando.

En este trabajo defiendo una interpretación diferente. Me parece que, como sostiene Wilburn 2016, la función dramática del discurso es provocar dudas en cuanto a la comprensión que Protágoras tiene acerca del bien y, por ende, sobre su aptitud como educador. Sin embargo, sostengo esta tesis por razones distintas. De acuerdo con mi interpretación, el discurso no expresa una posición relativista en torno al bien, sino sólo una postura pluralista. Ésta es, sin duda, rechazada por Platón; pero no por esta razón sugiere que la comprensión del sofista es inadecuada. Más bien, esto debe inferirse de la relación entre este pluralismo y el hedonismo que Protágoras acepta posteriormente; pues el segundo, tal y como es formulado por Sócrates, resulta incompatible con el primero. En efecto, de acuerdo con el pluralismo protagórico, el bien no es único sino múltiple; pero, según el hedonismo que el sofista termina aceptando, el bien es único y se identifica con el placer. Así, el maestro de Platón muestra que las opiniones de Protágoras sobre el bien son confusas, porque es llevado a asumir una posición inconsistente. De este modo, mi interpretación hace que el discurso acerca del bien, uno de los pocos lugares en donde el sofista expresa, por propia voluntad y sin ayuda de mitos, su opinión sobre alguno de los temas principales de la conversación, reciba una respuesta por parte de Sócrates. 
En la sección II presento brevemente el contexto previo al discurso, pues sólo de esta manera se puede entender su función dramática. En la sección III analizo a detalle el discurso, explicando con cuidado la posición pluralista que Protágoras manifiesta en éste. Finalmente, en la sección IV muestro cómo la discusión final sobre el hedonismo constituye una velada refutación del pluralismo expresado por dicho sofista anteriormente. De esta forma, Sócrates nos lleva a la conclusión de que Protágoras no es una persona competente para ocuparse de la educación de los jóvenes. Este sofista no sabe qué es el bien, el fin de la educación; ya que tiene opiniones contradictorias sobre el mismo.

\section{EL CONTEXTO}

El Protágoras comienza con el encuentro entre Sócrates y un compañero anónimo, al cual el filósofo le refiere que ha pasado el día dialogando con "el más sabio de entre los [hombres] actuales", Protágoras (Prt., 309d1). ${ }^{2}$ Ante la insistencia del compañero, Sócrates le narra el diálogo que sostuvo con el sofista de Abdera. La narración está precedida por una introducción (Prt., 310a-316b), en donde el maestro de Platón describe la manera en que llegó a conversar con Protágoras. Esta introducción es importante, pues precisa el fin último de la conversación entre ambos. El filósofo ateniense refiere que ese mismo día fue despertado por Hipócrates, un impetuoso joven, quien, al enterarse recientemente de la presencia de Protágoras en la ciudad, partió antes del alba a su casa para rogarle que intercediera por él ante el sofista. Aunque, en apariencia, Hipócrates tiene claro por qué quiere conocer al sofista, para que le transmita su sabiduría (Prt., 310d5-6), los cuestionamientos de Sócrates revelan que realmente ignora el tipo de enseñanza que ansía recibir. El filósofo le muestra a Hipócrates que ignora en qué es sabio Protágoras en tanto sofista y que, por tanto, no sabe si el confiarle a éste

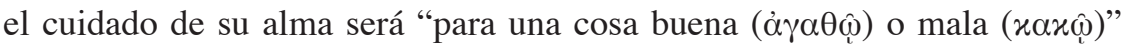
(Prt., 312c3-4). Así pues, Sócrates da una fuerte reprimenda a Hipócrates por pretender confiar, irreflexivamente, el cuidado de lo más importante que tiene, su alma, a las enseñanzas de alguien, sin conocer la naturaleza de las mismas, y sin saber, por tanto, si serán benéficas o perjudiciales para él.

Sócrates, de hecho, formula una hipótesis sobre la enseñanza que un sofista proporciona: " $¿$ acaso entonces, Hipócrates, el sofista resulta que es un cierto mercader y comerciante de las mercancías de las cuales se alimenta el alma? Pues a mí, al menos, me parece que es alguien asî" (Prt., 313c4-6).

\footnotetext{
2 Todas las traducciones del griego en este trabajo son nuestras. Para el griego del Protágoras, utilizo la edición de Burnet 1903.
} 
Es decir, el sofista parece ser un mercader o comerciante de "aprendizajes" ( $\mu \alpha \theta \eta \dot{\eta} \mu \alpha \alpha$, Prt., 313c7). Esta hipótesis permite que el maestro de Platón haga una analogía entre las cosas corporales y las anímicas. Los mercaderes y comerciantes de alimentos corporales sólo venden estos alimentos, pero ignoran si éstos son benéficos o dañinos para el cuerpo. Este conocimiento nada más lo tienen el maestro de gimnasia o el médico. De la misma manera, si el sofista es un mercader o comerciante, entonces únicamente vende ciertos aprendizajes, pero ignora si son benéficos o perjudiciales para el alma. Este conocimiento sólo lo posee el médico del alma (Prt., 313c-314a). De esta forma, queda establecido el principal eje temático del Protágoras. ${ }^{3}$

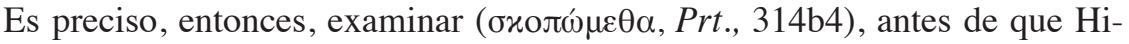
pócrates se entregue a las enseñanzas de Protágoras, si es que éste, en tanto sofista, es un mero mercader y comerciante de aprendizajes, o si realmente tiene conocimiento sobre lo que vende (Prt., 314bc); pues, si lo primero es cierto, sólo en caso de que Hipócrates fuera ya un médico del alma podría determinar si le conviene "comprar" las enseñanzas de Protágoras. Pero, dado que no lo es, sería mejor que se mantuviera alejado del sofista.

Tras esta conversación inicial, Sócrates e Hipócrates llegan a casa de Calias, en donde se encuentran Protágoras y otros muchos convidados, incluidos los sofistas Hipias y Pródico. Sócrates le pide a Protágoras que diga qué beneficio obtendrá Hipócrates de sus enseñanzas, las cuales está muy deseoso de tomar (Prt., 318a). Y es a partir de esta pregunta que se desarrolla todo el diálogo posterior entre el filósofo y el sofista. Esta conversación es muy extensa y compleja, por lo que es fácil perder de vista que el objetivo de Sócrates es examinar a Protágoras, examinar el valor de las enseñanzas que es capaz de proporcionar.

Protágoras explica cuál es el aprendizaje que ofrece del siguiente modo:

Este aprendizaje ( $\mu \alpha \dot{\theta} \theta \eta \mu \alpha)$ es la buena deliberación ( $\varepsilon \dot{\jmath} \beta o v \lambda i \alpha)$ acerca de los asuntos domésticos, cómo administrar mejor la casa propia, y acerca de los asuntos de la ciudad, cómo ser el más capaz en cuanto a los asuntos de la ciudad, tanto para actuar como para hablar (Prt., 318e5-319a29).

Sócrates interpreta el aprendizaje que el sofista profesa enseñar como equivalente a enseñar "la técnica política" ( tanto, Protágoras se compromete a "hacer a los varones buenos ciudadanos"

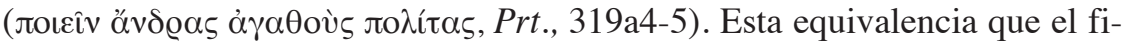
lósofo propone, y que el sofista acepta, tiene importantes consecuencias para el desarrollo posterior de la conversación. Sin embargo, aquí me limitaré a

\footnotetext{
${ }^{3}$ Otros autores que sostienen que esta cuestión constituye el eje temático alrededor del cual se desarrolla toda la conversación del Protágoras son Duncan 1978, p. 216, y Wilburn 2016, p. 226.
} 
señalar que, de acuerdo con ésta, el aprendizaje que Protágoras pretende enseñar es una "técnica" ( $\tau \dot{\varepsilon} \chi \vee \eta)$, un cuerpo especializado de conocimientos con un objeto de estudio definido, el que puede ser enseñado, y el cual conlleva una distinción entre el experto y el lego. Asimismo, en consonancia con una práctica habitual en los diálogos socráticos, la llamada "analogía de la techne ( $\tau \dot{\varepsilon} \chi v \eta)$ ", Sócrates pronto equipara a esta técnica política con

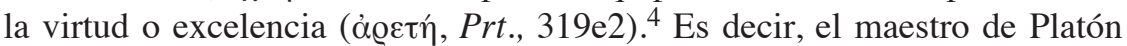
le presenta a su interlocutor la idea de que la virtud es una técnica y, así, el aprendizaje que el sofista profesa enseñar es reinterpretado como la enseñanza de la técnica política o virtud del ciudadano.

El desarrollo posterior del Protágoras puede entenderse como un examen de esta pretensión. Sócrates cuestiona, de diversos modos, la capacidad de su interlocutor para proporcionar en verdad este aprendizaje y, por ende, cuestiona que el sofista de Abdera tenga realmente el conocimiento que lo capacitaría para esta enseñanza. De esta manera, el filósofo intenta validar su hipótesis inicial: que Protágoras, y los sofistas en general, no tienen conocimiento de lo que dicen enseñar, sino que sólo venden la pretensión de ese aprendizaje.

La primera estrategia que Sócrates sigue para examinar al sofista consiste en cuestionar que exista en verdad tal técnica política, es decir, que la virtud del ciudadano constituya un cuerpo de conocimientos especializado y que, por tanto, sea enseñable (Prt., 319a-320c). No me detendré a analizar el argumento del filósofo, ni la respuesta de Protágoras, la cual consiste en un largo discurso en el que a través de un mito (Prt., 320c-322d) y una expli-

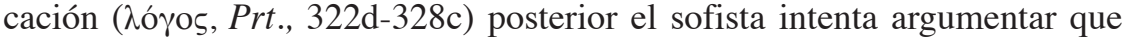
la virtud es enseñable. Baste decir que Sócrates no cuestiona directamente el mito, el lógos o la conclusión, sólo dice que está "ahora persuadido, salvo que [existe] para mí un pequeño obstáculo" (Prt., 328e3-4).

El pequeño obstáculo consiste en una duda sobre la naturaleza de la virtud misma. El filósofo refiere que, en su largo discurso, el sofista ha hablado de tres virtudes: prudencia, justicia y piedad. La duda de Sócrates es: "si acaso la virtud es algo uno, y partes de ésta son la justicia, prudencia y piedad, o estas cosas a las que yo ahora me refería son todas nombres de un único ser" (Prt., 329c6-d1). Es decir, la pregunta es si la virtud es una porque las virtudes particulares, a las que se añaden la sabiduría y la valentía, son todas distintos tipos o especies de un mismo género, o si la virtud es una porque en realidad no hay virtudes particulares, sino que todas éstas son sólo maneras

\footnotetext{
${ }^{4}$ Sobre el uso socrático de la analogía de la techne, cf. Roochnik 1986. Algunos pasajes en donde Sócrates utiliza la analogía de la techne son: Chrm., 165c-176d, ed. 1903; Euthd., 291b293a, ed. 1903; Euthphr., 13a-14b, ed. 1995; Grg., 447-461, ed. 1903; Ion, 531b-533d, ed. 1903; La., 192d-193d y 195a-c, ed. 1903.
} 
de designar a una virtud única. De acuerdo con la primera opción, ninguna virtud sería reductible a la otra, así que para ser completamente virtuoso habría que tenerlas todas. De acuerdo con la segunda, todas las supuestas virtudes particulares serían reductibles a una sola. Protágoras elige defender la primera opción (Prt., 329d8-e2). Y Sócrates se dedica a cuestionar esta elección, intentando mostrar que, en última instancia, todas las virtudes se reducen a una sola: la sabiduría o conocimiento. Esta discusión, compleja y de no fácil interpretación, dominará el resto de la conversación. Sin embargo, no debemos perder de vista que ésta constituye una segunda estrategia general que el filósofo sigue para poner en entredicho la capacidad del sofista como educador, su estrategia consiste en mostrar que Protágoras ignora lo que es la virtud, aquello que, supuestamente, él es capaz de enseñar.

Esta segunda estrategia general tiene diversas partes. En la primera, Sócrates desarrolla varios argumentos para mostrar la identidad entre dos pares de virtudes: entre la justicia y la piedad (Prt., 330b6-331b8), y entre la sabiduría y la prudencia (Prt., 332a4-333b3). Para avanzar el argumento de que todas las virtudes se reducen a la sabiduría, el maestro de Platón requeriría mostrar, además, que la justicia o la piedad son idénticas a la sabiduría o a la prudencia. Es en el contexto de ese argumento, en el que Sócrates aparentemente intenta mostrar que la justicia y la prudencia son lo mismo, que Protágoras introduce su discurso sobre el bien.

El filósofo le pregunta a su interlocutor si cree que es posible que alguien

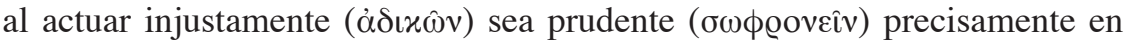

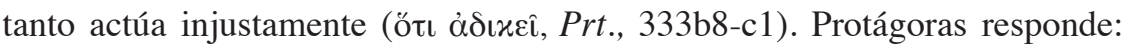
"a mí, al menos, me daría vergüenza estar de acuerdo con esto, aunque ciertamente muchos hombres lo afirman" (Prt., 338c1-3). Sócrates pregunta si debe entonces elaborar el argumento ( $\lambda$ ó $\gamma \circ \varsigma)$ con aquellos hombres o con él; y el sofista responde que primero discuta el argumento "de los muchos ( $\tau \hat{\omega} \mathrm{v}$

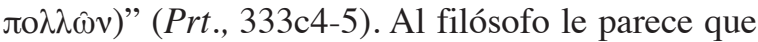

No hay ninguna diferencia para mí, si sólo tú respondes, sea que a ti estas cosas te parezcan así o no. En efecto, al menos yo, examino ( $\dot{\varepsilon} \xi \varepsilon \tau \alpha \dot{\zeta} \zeta(\omega)$ principalmente el argumento $(\lambda o ́ \gamma o \varsigma)$, aunque quizás resulta ( $\sigma 0 \mu \beta \alpha$ ível) que tanto yo, el que pregunta, como el que responde seamos examinados (Prt., 333c6-9).

Parece extraño que Sócrates afirme que le da lo mismo si Protágoras piensa o no que la opinión de los muchos es correcta, pues una de las reglas básicas del diálogo socrático es que es necesario que el interlocutor diga lo que realmente piensa. ${ }^{5}$ Sin embargo, el maestro de Platón hace una suge-

${ }^{5}$ Cf. Crit., 49c11-d2, ed. 1995; Euthd., 286d, ed. 1903; Grg., 495a5-9 y 500b5-7, ed. 1903; Prt., 331c4-d1, ed. 1903; R., 337c y 346a3-4, ed. 2003. Sobre esta regla, cf. también Vlastos 1983, p. 35, y Benson 1989, pp. 594-596. 
rencia importante, que quizá se dé un resultado concomitante al examinar la opinión de los muchos: que sean examinados tanto él como Protágoras. Con esto, Sócrates propone principalmente dos cosas. En primer lugar, indica de nuevo que, además de la discusión misma del asunto en cuestión, a él le interesa examinar al sofista. Es decir, examinar su estatus en tanto maestro de sabiduría y de virtud en general. Y, por otro lado, sugiere que el examen de la opinión de la mayoría podría quizá resultar en un examen de Protágoras, en tanto que tal vez también él sostiene esta opinión de la que dice avergonzarse. 6

El filósofo procede entonces al examen de la opinión de la mayoría, "que algunos al cometer injusticia son prudentes (owф@oveîv)" (Prt., 333d4). Pregunta entonces a Protágoras:

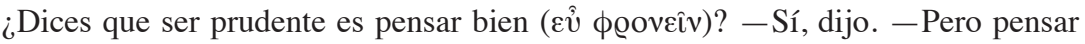
bien es deliberar bien ( $\varepsilon \hat{v} \beta$ ßov $\lambda \varepsilon v \varepsilon \sigma \theta \alpha \iota)$, en tanto que actúan injustamente. - Sea,

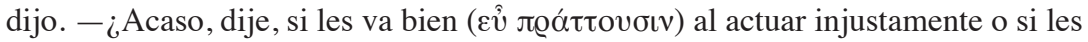
va mal? - Si bien. — ¿Dices entonces que algunas cosas son buenas? - Lo afirmo (Prt., 333d5-8).

Es importante aquí la conexión que Sócrates establece entre "ser pru-

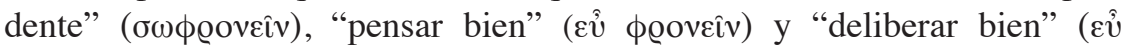

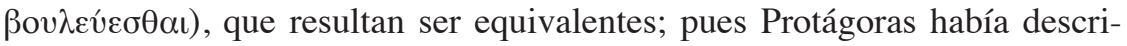
to el aprendizaje que él pretende enseñar como la "buena deliberación"

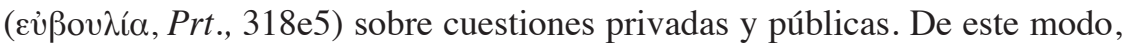
Sócrates sugiere sutilmente que lo que enseña el sofista, la buena deliberación ( $\varepsilon u ̉ \beta o v \lambda i ́ \alpha)$, podría ser quizá compatible con el comportamiento injusto.

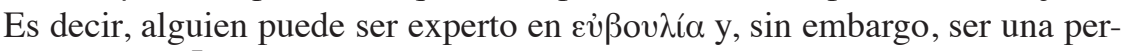
sona injusta. ${ }^{7} \mathrm{Si}$ así fuera, las enseñanzas de Protágoras serían peligrosas; porque realmente no estarían dirigidas a promover la virtud de sus discípulos, sino a desarrollar una habilidad discursiva y lógica que igual puede servir para realizar buenas o malas acciones. En este sentido, la posición de Protágoras se acercaría un poco a la de Trasímaco en República, I, quien abiertamente sostiene que la injusticia es preferible a la justicia, y que la pri-

\footnotetext{
${ }^{6}$ Difiero, así, de la interpretación de Taylor, en Plato 1991, pp. 131-32, de este pasaje, pues sugiere que la única manera en que Protágoras podría ser examinado al discutir la opinión de la mayoría es con respecto a su habilidad para defender una tesis.

${ }^{7}$ Esto mismo es sugerido también sutilmente por Platón cuando Protágoras, en el Gran Discurso, alega como evidencia de que todos creen que es necesario que todos participen de la justicia la siguiente disparidad entre las técnicas especializadas y la virtud (Prt., 323a5-c2): en el caso de las primeras, cuando alguien no posee la técnica lo prudente es que lo reconozca; mientras que en el caso de la virtud, cuando alguien es injusto y es reconocido como tal, incluso

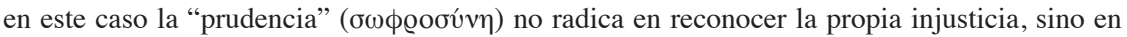
ocultarla, pues decir la verdad sería "locura" ( $\mu \alpha v i ́ \alpha)$.
} 


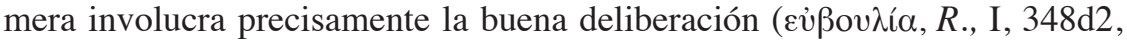
ed. 2003) ${ }^{8}$ Sin embargo, el examen de la opinión de la mayoría no concluye y, por tanto, no se revela, en este momento, si Protágoras realmente sostenía que los injustos pueden ser prudentes o deliberar bien. ${ }^{9}$

Sócrates le pregunta a su interlocutor si reconoce que hay algunas cosas buenas. Evidentemente, su objetivo es dirigir la atención al fin hacia el cual tiende la acción, el bien. De este modo, el filósofo quizás hubiera cuestionado que la persona que pretende deliberar bien, al actuar injustamente, realmente lo haga, pues, en última instancia, a esa persona no le va bien, no

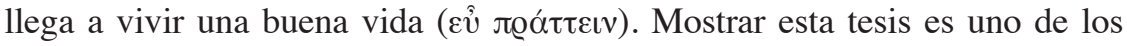
principales retos que Platón enfrentó, en particular, en la República. En efecto, los libros II-X pueden verse como un intento de responder a la posición similar de Trasímaco defendida en el libro I. En cualquier caso, el argumento del Protágoras se ve interrumpido, porque las preguntas de Sócrates dan pie a que el sofista de Abdera pronuncie un interesante discurso sobre el bien. En la siguiente sección, me ocuparé de examinarlo. Como veremos en esa sección y en la posterior, el tema del bien es central para mostrar que Protágoras no es un educador competente. Incluso si el sofista no subscribe la tesis de que es posible ser injusto y prudente (o deliberar bien), si desconoce cuál es el bien que la vida humana debe perseguir, la enseñanza de la "buena deliberación" podría tener las consecuencias que Sócrates sugiere: ser usada para propósitos injustos. La única manera en que Protágoras podría orientar correctamente a sus discípulos es si les enseña, al mismo tiempo que esta habilidad, qué es el bien, es decir, el fin hacia el cual deben dirigirla; pero, como veremos, la conclusión que el maestro de Platón sugerirá es que su interlocutor desconoce qué es el bien.

\section{El discurso de Protágoras SOBRe El BiEN}

En la sección anterior vimos que la discusión entre Sócrates y Protágoras obedece al propósito de examinar si el sofista en verdad tiene conocimiento sobre los aprendizajes que vende o si, como el filósofo sospecha, sólo es un mero comerciante de aprendizajes. Si se trata de lo segundo, no sería conveniente que Hipócrates recurra a las enseñanzas del sofista. El discurso acerca del bien se inserta dentro de la segunda estrategia de Sócrates para mostrar

\footnotetext{
${ }^{8}$ Hay otras similitudes entre esta parte del Protágoras y República, I. Por ejemplo, en el

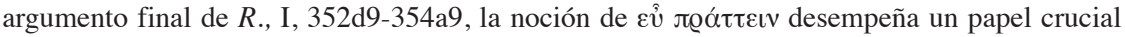
(cf. Prt., 353e5), y se explota la ambigüedad de esta frase, que puede significar, por un lado, que las cosas salgan bien, es decir, que algo vaya bien, y por otro, simplemente "actuar bien".

${ }^{9}$ Wilburn 2016, p. 241, parece asumir que ésta es realmente la posición de Protágoras, pero no menciona las similitudes que hay con la posición de Trasímaco en $R$., I.
} 
que Protágoras no tiene conocimiento sobre aquello que profesa enseñar, la "buena deliberación", entendida como la técnica o virtud política; pues el sofista defiende que hay varios tipos irreductibles de virtud (sabiduría, prudencia, justicia, piedad, valentía), mientras que el filósofo ha desarrollado argumentos para mostrar que éstas son realmente una sola (la sabiduría, como argumentará luego). En el curso del último argumento, que intenta mostrar que la justicia se reduce a la prudencia, Protágoras introduce el discurso en cuestión. El razonamiento queda inconcluso, porque el desarrollo del mismo ha suscitado la pregunta de si es posible ser injusto y prudente al mismo tiempo. Y esta pregunta ha llevado a un cuestionamiento sobre el bien, esto es, sobre el fin último al que tiende el comportamiento humano, y al cual se pretende llegar teniendo, conforme a la virtud, una vida prudente y sabia.

Sócrates pregunta: "¿dices entonces que existen algunas cosas buenas?" (Prt., 333d8). Protágoras responde afirmativamente. Luego el filósofo propone una caracterización de las cosas buenas: “¿acaso, entonces, estas cosas son buenas, las que son útiles ( $\dot{\phi} \varepsilon \hat{\lambda} \lambda \mu \alpha)$ para los hombres?" (Prt., 333d8e1). El sofista no está de acuerdo, pues sugiere que esta caracterización proporciona una condición suficiente para ser bueno, pero no una condición necesaria: "Sí, por Zeus, e incluso si no fueran útiles para los hombres, yo, al menos, las llamaría buenas" (Prt., 333e1-2). Sócrates intenta aclarar si su interlocutor piensa que las cosas buenas son útiles, aunque no necesariamente útiles para los hombres, o si algunas cosas buenas lo son sin ser útiles a ninguna cosa: "¿Acaso te refieres a las cosas que no son útiles a ninguno de los hombres, o a las que no son útiles en absoluto? ¿Y a tales cosas tú llamas buenas?" (Prt., 333e5-334a2).

Protágoras responde con un discurso sobre el bien:

De ningún modo - dijo-. Sino que sé que muchas cosas son dañinas para los hombres, alimentos, bebidas, medicamentos y otras miles de cosas, pero otras son benéficas. Mientras que otras no son ni lo uno ni lo otro para los hombres, pero sí lo son para los caballos. Otras, sólo para los bueyes, y otras para los perros. Otras para ninguno de éstos, pero sí para los árboles. Otras son buenas para las raíces del árbol, pero malas para los retoños. Por ejemplo, el estiércol aplicado a las raíces de todas las plantas es bueno, pero, si quisieras echarlo sobre los brotes y las ramas nuevas, se destruirían completamente. En tanto que el aceite es muy perjudicial para todas las plantas y lo más adverso para los cabellos de los animales distintos al hombre, pero para los cabellos del hombre, y para el resto de su cuerpo, es protec-

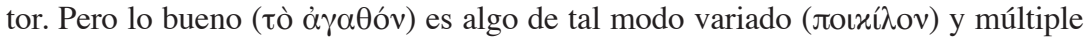
( $\pi \alpha v \tau o \delta \alpha \tau o ́ v)$ que, incluso aquí, esto mismo es bueno para el exterior del cuerpo del hombre, pero lo peor para el interior. Y por esto todos los médicos les prohíben a los enfermos usar aceite, salvo muy poco en aquellas cosas que van a comer, solamente cuanto elimine los olores molestos que se dan en los alimentos y los aderezos (Prt., 334a3-c6). 
Este discurso parece, a primera vista, muy importante; pues Protágoras expresa directamente, sin ayuda de mitos, una opinión substantiva sobre uno de los principales asuntos tratados. Por ello, muchos autores han visto en éste la manifestación de una doctrina propia, característica del pensamiento del sofista; pero ha resultado difícil precisar qué doctrina es ésta. Asimismo, parece extraño que Sócrates no haga ninguna réplica al sofista, ni de inmediato, ni en el transcurso de la conversación. En efecto, el maestro de Platón se queja de que la respuesta de Protágoras es muy larga y que él, siendo tan olvidadizo, necesita respuestas más cortas. Esto suscita un prolongado debate sobre cómo debe continuarse la conversación. Después, Sócrates nunca se refiere explícitamente a la opinión del sofista expresada en este discurso. Por eso, no es obvio qué papel desempeña éste. En esta sección trataré de dilucidar la doctrina expuesta por Protágoras en este discurso, y en la próxima retomaré lo concerniente a su función.

Varios intérpretes han sostenido que la doctrina sobre el bien que el sofista de Abdera expresa aquí es una forma de relativismo. ${ }^{10}$ Esta interpretación ha parecido bastante natural, en tanto que históricamente se ha identificado a Protágoras como un relativista, de hecho, como el relativista por excelencia. En el Teeteto, Sócrates le atribuye una posición que en apariencia es una forma de relativismo metafísico, la famosa doctrina de que el hombre es la medida de todas las cosas (Tht., 152a2-4, ed. Duke et al. 1995), discutida a fondo en ese diálogo. La fama posterior de Protágoras como un relativista proviene, de hecho, principalmente del Teeteto. Sin embargo, como varios autores han señalado, la posición sobre el bien manifestada por el sofista en el Protágoras no parece ser una forma de relativismo, ${ }^{11}$ si por relativismo sobre $F$ entendemos la tesis de que el que $x$ sea $F$ no es nunca el caso simpliciter, sino que siempre es relativo a un cierto marco de evaluación. ${ }^{12} \mathrm{Tal}$ marco introduce un elemento subjetivo, pues típicamente está constituido por algún tipo de estructura dependiente de un sujeto (convenciones y normas sociales o estándares individuales). Así, un relativista en torno al gusto piensa que el que el café sea delicioso no es el caso simpliciter, sino que sólo es relativo a un marco de evaluación, por ejemplo, un cierto estándar subjetivo individual (o social) de gusto. Pero, relativo a otro marco de evaluación, o estándar subjetivo, no es el caso que el café sea delicioso.

Ahora bien, recordemos que Protágoras introduce este discurso para explicar por qué sostiene que no todas las cosas buenas son buenas (es decir, útiles) para los hombres, sino que hay cosas buenas que sólo son buenas

\footnotetext{
10 Por ejemplo Adam y Adam, en Plato 1893, p. 138; Divenosa, en Platón 2006, p. 164; Rowett 2013; Taylor 1927,p. 251; Versenyi 1962, p. 179, y Vlastos 1956, p. xvi.

${ }^{11}$ Cf. Kerferd 1949; McCoy 1998; Moser y Kustas 1966; Taylor, en Plato 1991, pp. 133-

${ }^{12} \mathrm{Cf}$., por ejemplo, Wright 2008.
} 134. 
para otras cosas, mas no para los hombres. Por ejemplo, el estiércol no es bueno para los hombres, pero es bueno para las raíces de las plantas. En el curso de esta explicación menciona varios ejemplos de cosas que son buenas para $x$, mas no son buenas para $y$, incluso cuando $x$ y $y$ son partes de una misma cosa. Por ejemplo, el aceite es bueno para las partes exteriores del hombre, pero no es bueno para las partes interiores. De este modo, lo que dice el sofista parece implicar ciertamente que el que $x$ sea bueno nunca es el caso simpliciter, sino que algo es bueno (útil) sólo en relación con, para, ciertas cosas.

Sin embargo, es muy notorio que en esta doctrina está ausente cualquier elemento subjetivo de evaluación. Protágoras nunca sugiere que el que $x$ sea bueno depende de algún factor subjetivo, como normas, convenciones sociales o algún tipo de rasgo subjetivo individual como el gusto o la perspectiva. El que el aceite no sea bueno para las partes internas del hombre no parece depender, para el sofista, de alguna convención o apreciación subjetiva de nadie. La explicación que proporciona para apoyar este ejemplo parece confirmar esto. Protágoras afirma que "por esto todos los médicos les prohíben a los enfermos usar aceite, salvo muy poco en aquellas cosas que van a comer, solamente cuanto elimine los olores molestos que se dan en los alimentos y los aderezos" (Prt., 334c2-6). Es decir, el que los médicos limiten la ingestión de aceite a sus enfermos es evidencia de que éste no es bueno para las partes internas del hombre, pues, estando enfermo, el cuerpo humano está débil y el efecto dañino del aceite puede incrementarse. Esta limitación sugiere que los griegos tendían a consumir más aceite cuando no estaban enfermos, simplemente porque consumirlo con los alimentos puede ser agradable. Así pues, el que el aceite no sea bueno para las partes internas del cuerpo no parece ser relativo a ningún elemento subjetivo de apreciación, ya que era una costumbre griega ingerir aceite y era algo que los griegos disfrutaban. La limitación en la ingestión de aceite va en contra de una convención social, y del gusto individual, y parece basarse enteramente en el conocimiento que proporciona la ciencia médica. Por ello, el ejemplo de Protágoras parece sugerir que el que el aceite no sea bueno para las partes internas del cuerpo humano es algo objetivo que tiene que ver sólo con las propiedades del aceite y con la constitución física del cuerpo, independientemente de las costumbres culinarias y del gusto subjetivo.

No obstante, varios autores han considerado que, de cualquier modo, es razonable pensar que Platón sugiere que la posición de Protágoras es relativista, sencillamente porque en el Teeteto parece atribuirle esa posición. ${ }^{13}$ Algunos estudiosos han respondido argumentando que es crucial interpretar los diálogos de Platón por sí mismos, de manera que, si un diálogo $A$ no

\footnotetext{
${ }^{13}$ Por ejemplo, Wilburn 2016, p. 230, n. 10.
} 
justifica cierta interpretación, no es correcto adoptarla de cualquier modo sólo porque en otro diálogo $B$ ésta parece ser sostenida. ${ }^{14}$ Estoy de acuerdo con este principio metodológico, pero hay además otra razón en contra de leer en este discurso la posición relativista que parece atribuírsele al sofista de Abdera en el Teeteto: en el Protágoras, el sofista expresa por sí mismo su opinión sobre el bien, mientras que, en el Teeteto, Platón aclara que aquél ya está muerto y que, por tanto, no puede expresar por sí mismo sus opiniones. Por eso, Sócrates tiene que "revivir" a Protágoras para que defienda su posición. De este modo, en el único lugar donde Platón tiene la oportunidad de hacer que dicho sofista exprese claramente una postura relativista no lo hace. Y en el lugar en donde Platón parece atribuirle esa posición, Protágoras ya no puede confirmar que realmente la acepta. Que Platón se haya tomado el trabajo de indicarnos eso en el Teeteto me parece muy significativo; por ello, resulta aún más inverosímil tratar de leer el Teeteto en el Protágoras.

Pero, si la posición de Protágoras no es un relativismo, ¿qué es entonces? Algunos comentadores han planteado que, en todo caso, dicha postura relacional no es rechazada por Platón; ya que, argumentan, éste acepta que las cosas sensibles buenas son siempre buenas con relación a algo. ${ }^{15}$ En efecto, para Platón, una cosa sensible es sólo justa, buena o bella, en relación con otra cosa, nunca en sí misma. ${ }^{16}$ Sin embargo, como Wilburn 2016, pp. 229-230, ha sostenido, la posición sugerida por Protágoras no podría ser aceptada por Platón; porque el sofista afirma que "lo bueno es algo de

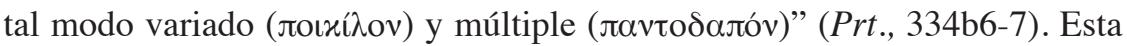
afirmación parece ser una tesis general sobre lo bueno, y no sólo sobre algunas cosas buenas. Además, los términos 'variado' (лоเxínov) y 'múltiple' ( $\pi \alpha v \tau o \delta \alpha \tau o ́ v)$ son generalmente usados por Platón, como Wilburn señala, para caracterizar cierto tipo de diversidad o multiplicidad que le parece inapropiada. A continuación menciono los pasajes más relevantes.

En el Menón y en el Teeteto, esos términos son utilizados por Sócrates para caracterizar intentos insatisfactorios de definición. En el Teeteto, el protagonista homónimo trata de contestar a la pregunta de qué es conocimiento ofreciendo varios tipos o casos particulares de conocimiento, como la geometría o la técnica del zapatero (Tht., 146c-d, ed. Duke et al. 1995). Sócrates observa que Teeteto "habiéndole sido pedida una cosa, ha dado

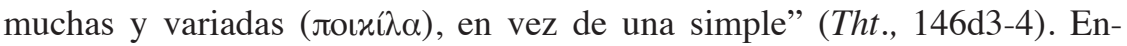
tonces el filósofo intenta hacer que su interlocutor comprenda que lo que él

\footnotetext{
14 Kerferd 1953, p. 45; Moser y Kustas 1966, p. 113, n. 6; Schiller 1908, p. 523. Wilburn 2016, p. 233, n. 14, cuestiona esta estrategia.

${ }^{15}$ Moser y Kustas 1966, p. 114, y Taylor 1991,p. 134.

${ }^{16} \mathrm{Cf}$., por ejemplo, $R$., V, 479a-c, ed. 2003.
} 
quiere es una explicación de qué es el conocimiento en sí y no una lista de tipos de conocimiento.

Por su parte, en el Menón, el personaje que da nombre al diálogo se sorprende porque Sócrates no sabe qué es la virtud, pues piensa que no es en absoluto difícil explicar qué es. Menón menciona diferentes tipos o ejemplos particulares de virtud: señala cuál es la virtud del varón, la virtud de la mujer, etcétera. El filósofo ateniense responde que es muy afortunado, pues si bien "una virtud estoy buscando, un enjambre de virtudes he hallado que tú has proporcionado" (Men., 72a7-8, ed. Burnet 1903). A continuación, Sócrates prosigue con la analogía entre virtudes y abejas y le pregunta a Menón qué opinaría si el objetivo fuera explicar qué es una abeja. Si Menón hubiera dicho similarmente que las abejas "son muchas y

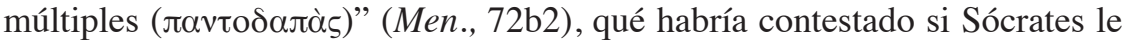
hubiera preguntado lo siguiente: “¿acaso dices que son muchas y múltiples

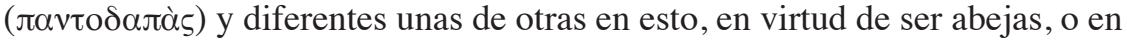
esto en nada difieren, sino en otra cosa, como en belleza, magnitud, o alguna otra cosa similar" (Men., 72b3-6). Su interlocutor responde que en tanto abejas en nada difieren. Y Sócrates pretende entonces aplicar la misma idea

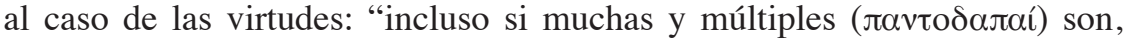
todas tienen la misma cierta forma (عî̉os) única, por la cual son virtudes" (Men., 72c6-8).

Wilburn asimila ambos casos, piensa que la incapacidad de Teeteto y Menón de ver lo que hay en común en los diferentes ejemplos de conocimiento y virtud "is taken as a sign of their ignorance" (2016, p. 230). El especialista no llega a sostener que el caso de Protágoras es exactamente igual al de Teeteto y Menón, pero sugiere que "Protagoras' use of poikilon and pantodapon, therefore, shows at least that his characterization of goodness is not one that Socrates or Plato would find satisfying taken by itself" (Wilburn 2016, p. 230). La razón por la cual no asimila estos tres casos es "because Socrates does not immediately press the sophist, as he does with Theaetetus and Meno, to provide a unified account of the good, it is left open at this point how Protagoras would respond to further questioning on the matter" (idem).

Sin embargo, me parece que hay una diferencia importante entre las posiciones de Teeteto y Menón que Wilburn pasa por alto. Teeteto da una lista de tipos de conocimiento, y, en cuanto comprende que Sócrates quiere una definición unitaria de conocimiento, reconoce que no es capaz de proporcionarla, aunque ve que este caso es similar al de intentar dar una definición unitaria de nociones matemáticas como las potencias (Tht., 148b6-c1, ed. Duke et al. 1995). En cambio, Menón sugiere explícitamente desde el principio que las virtudes son diferentes (cf. Men., 71e8, ed. 1903), y en cuanto comprende que lo que quiere Sócrates es una definición unitaria de 
virtud, similar a una definición unitaria de la salud o de la fuerza, rechaza que los casos sean similares: "me parece Sócrates, al menos a mí, que de algún modo éste ya no es similar a estos otros" (Men., 73a4-5). Así, la posición sugerida por Menón no parece ser, como la de Teeteto, producto de una mera incapacidad para comprender la unidad sobre la multiplicidad, sino que parece ser una posición, más filosófica, de negación explícita de la unidad de la virtud.

La postura de Protágoras se asemeja más a la de Menón que a la de Teeteto. ${ }^{17}$ Es Protágoras mismo quien explícitamente señala que lo bueno es "variado" y "múltiple". Lejos de dar inadvertidamente una propuesta sobre qué es lo $F$ (el bien) que, de acuerdo con el diagnóstico de Sócrates, tiene el defecto de ser variada y múltiple, el sofista de Abdera afirma que lo $F$ es variado y múltiple. Su posición parece, entonces, una posición filosófica substantiva sobre lo $F$; pues es una negación explícita de que lo $F$, el bien, es unitario. Me parece que esta postura de Protágoras no es, como hemos visto, un relativismo, sino un pluralismo sobre el bien. El pluralismo sobre lo $F$ es una negación del monismo sobre lo $F$. El pluralismo es distinto del monismo porque niega que haya una sola manera de ser $F$. Por el contrario, sostiene que hay muchas maneras, irreductibles a una sola, de ser $F$. Pero el pluralismo es también distinto del relativismo, porque el primero no involucra un compromiso con la tesis de que los hechos sobre lo $F$ son relativos a un marco subjetivo de evaluación. El pluralismo es enteramente compatible con el objetivismo, con que sea una cuestión objetiva, independiente de cualquier marco subjetivo de evaluación, que lo $F$ sea el caso. ${ }^{18}$ Así, de acuerdo con el pluralismo sobre lo $F$, no hay una sola propiedad (objetiva) de lo $F$, sino varias propiedades (objetivas) irreductibles de lo $F$. Por ello, la diferencia entre el relativismo y el pluralismo sobre el bien consiste en que, para el primero, el que $x$ sea bueno es relativo enteramente a un marco subjetivo de evaluación, de modo que $x$ puede ser bueno de acuerdo con los estándares de evaluación subjetiva de un sujeto S1, pero malo para los estándares de un sujeto S2. En cambio, para un pluralista sobre el bien, el que $x$ sea bueno no es sólo un tipo de hecho, hay varias propiedades de lo

\footnotetext{
${ }^{17}$ Recordemos que Sócrates sugiere que Menón es seguidor del otro gran sofista, Gorgias, y que Menón sostiene la mismas opiniones sobre la virtud que este último: "pues seguramente a ti te parecen las cosas que a aquél" (Men., 71d1-2, ed. 1903).

18 Sobre el pluralismo en general, y acerca del pluralismo antiguo en particular, cf. Apfel 2011, especialmente pp. 8-24, donde discute las características básicas del pluralismo. Apfel, de hecho, considera que el pluralismo está necesariamente comprometido con el objetivismo. Defiende que Protágoras es un pluralista moral y metafísico, no un relativista, aunque su análisis con respecto al Protágoras se basa principalmente en la posición del sofista sobre las virtudes, y no le da la suficiente importancia al discurso en torno al bien (cf. caps. II y III, especialmente pp. 96-99).
} 
bueno y, por ello, el que $x$ sea bueno puede consistir en varias cosas: que $x$ sea bueno ${ }_{1}$, que $x$ sea bueno ${ }_{2} \ldots$.. que $x$ sea bueno . .

Tomemos como ejemplo, para ilustrar esta distinción, el caso del aceite de oliva mencionado por Protágoras. Desde el punto de vista de un relativista, el que el aceite sea bueno es siempre relativo a un marco subjetivo de evaluación. El aceite puede ser bueno, como alimento, para una cierta comunidad $x$ que lo juzga como bueno; pero, al mismo tiempo puede ser malo, como alimento, para otra cierta comunidad $y$ que lo juzga como malo. De este modo, no hay un hecho objetivo sobre si el aceite es bueno, como alimento, sino múltiples hechos subjetivos. En cambio, desde el punto de vista del pluralista, el aceite puede tener la propiedad de ser malo-1, malo como alimento, mas este hecho no depende de ningún marco subjetivo de evaluación, sino que es un hecho enteramente objetivo: comer aceite en exceso es malo para cualquier ser vivo. Pero, al mismo tiempo, el aceite puede tener la propiedad de ser bueno-2, bueno como hidratante del cabello humano, éste es un hecho objetivo: el aceite es benéfico para cualquier ser vivo que tenga un cabello similar al de los seres humanos. De esta manera, el ser bueno no consiste en un solo tipo de hecho, pero cada uno de estos múltiples tipos de hecho es algo objetivo que no depende de la apreciación de un sujeto. Por ello es que, en principio, parece posible tener conocimiento de lo bueno, en el caso del pluralismo. Mientras que, en el caso del relativismo, no es posible tener conocimiento de lo bueno, sino sólo de las preferencias o juicios de los sujetos. Si bien es claro que Platón rechaza tanto el relativismo como el pluralismo, este último ha parecido preferible a muchos filósofos porque puede darle un lugar a la objetividad y al conocimiento. ${ }^{19}$

Platón claramente rechaza el pluralismo, la posición sobre el bien de Protágoras, porque, para él, hay una sola propiedad de lo bueno, la cual hace que todas las cosas buenas sean buenas, a la cual se reduce cualquier otra propiedad particular de lo bueno: la Forma del bien. Este filósofo es un monista sobre el bien. Por consiguiente, la postura de Protágoras acerca del bien es una posición filosófica substantiva que niega una tesis central de la metafísica y la ética platónicas, por tanto, no puede ser desestimada como una mera confusión, producto de la ignorancia, sino que necesita argumentos más elaborados. Resulta, por esto mismo, muy notorio que, aparentemente, Platón no atienda el discurso de Protágoras en absoluto. Sin embargo, considero que Platón sí ataca el pluralismo de este sofista y que, por ende, el

\footnotetext{
${ }^{19}$ Por ejemplo, Harman 1975 es un relativista sobre el bien, y Aristóteles, Thomson 1997 y Ross 1930 son pluralistas sobre el bien. Platón, por supuesto, piensa que también el pluralismo hace que el conocimiento acerca del bien no sea posible, pero esto es así porque emplea criterios epistemológicos muy demandantes, como en el argumento final de $R$., V, que implican que sólo las Formas pueden ser objetos de conocimiento.
} 
discurso de Protágoras sobre el bien tiene una función y una respuesta muy específicas en el diálogo, como veremos en la última sección. ${ }^{20}$

\section{PluRAlismo sobre El BIEN Y HEDONISMO}

El discurso de Protágoras sobre el bien expresa, como hemos visto, una posición filosófica substantiva, un pluralismo en torno al bien, de acuerdo con el cual no hay una sola propiedad de lo bueno, sino muchas propiedades irreductibles. Esta postura es rechazada por Platón, quien es un monista; para él, existe una única propiedad superior de lo bueno, la Forma del Bien, la cual hace que todas las cosas buenas sean buenas. Sin embargo, Sócrates no hace ninguna observación acerca del pluralismo expresado por Protágoras, tan sólo se queja por la extensión del discurso y solicita al sofista que abrevie sus respuestas, pues él es muy olvidadizo (Prt., 334c9-d1). El maestro de Platón, por supuesto, está siendo irónico, de modo que su queja es una maniobra para no responder directamente al discurso y desviar la atención hacia la cuestión formal de cómo continuar la conversación. La discusión de este asunto constituye un largo interludio (Prt., 334c-338e), en donde varios de los presentes dan su parecer al respecto. Ya al final, acuerdan que Protágoras sea ahora quien pregunte, para que Sócrates le muestre cómo se debe responder brevemente (Prt., 338d-e).

Pero, incluso si el filósofo ateniense no responde directamente al discurso del sofista, esto no implica que no conteste de una manera más sutil. Es claro que en la parte posterior al interludio no se encuentra esta respuesta, pues la atención se centra ahí en el análisis de un poema de Simónides (Prt., 338e-347a). Tras concluir esta parte, Sócrates vuelve al tema de la unidad de la virtud, que había sido interrumpido precisamente por el discurso de Protágoras. El filósofo intenta refutar el pluralismo protagórico sobre la virtud, pero su refutación no necesariamente equivale a una refutación del pluralismo en torno al bien. El que la virtud se reduzca a la sabiduría es compatible con la existencia de diferentes tipos irreductibles de bien. En ese caso, el ser virtuoso involucraría el conocimiento de los distintos tipos de bien y de las acciones apropiadas en cada contexto. Por ello, no creo que la respuesta al pluralismo sobre el bien de Protágoras se encuentre en esta refutación. La respuesta se halla, más bien, en la discusión sobre el placer, que ocurre dentro del debate sobre la unidad de la virtud, como mostraré a continuación.

\footnotetext{
${ }^{20}$ Esta caracterización de la posición de Protágoras en torno al bien como pluralista armoniza perfectamente con su postura sobre la virtud. Como hemos visto, de acuerdo con Protágoras, hay varias virtudes y éstas no son reductibles a una sola.
} 
En Prt., 349a-b, Sócrates retoma el tema de la unidad de la virtud, elaborando un resumen de la discusión anterior, sin hacer ninguna referencia al discurso de Protágoras sobre el bien. Tras este resumen, el sofista concede que el maestro de Platón ha mostrado que cuatro de las virtudes - la sabiduría, la prudencia, la justicia y la piedad - son "prácticamente casi

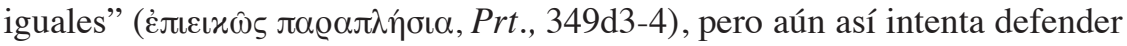
un pluralismo más restringido, argumentando que otra virtud, la valentía, es distinta a todas estas (Prt., 449d4-8). Sócrates formula un argumento para mostrar que la valentía y la sabiduría son lo mismo (Prt., 349e1-350c5). Protágoras critica el argumento y la conversación parece estancarse (Prt., 350c6-351b2). Es entonces cuando el filósofo reintroduce el tema del bien, de manera similar a cuando introdujo este asunto para avanzar su argumento a favor de la identificación de la justicia con la prudencia (Prt., 333d8), justo antes del discurso de Protágoras sobre el bien. Ahora, Sócrates le pregunta al sofista: "¿pero dices que algunos hombres viven bien y otros mal?" (Prt., 351b3-4). La similitud entre estos dos pasajes no es casual. El tema del bien parece ser concebido como crucial para mostrar la unidad de la virtud. Sin embargo, en el pasaje anterior la estrategia argumentativa del filósofo se vio interrumpida por la introducción de la propia concepción protagórica acerca del bien: el pluralismo. En esta ocasión, Sócrates avanza por cuenta propia una hipótesis sobre el bien, la posibilidad de que el hedonismo sea verdadero, es decir, la posibilidad de identificar al bien con el placer y al mal con el dolor.

En primer lugar, el filósofo le pregunta a Protágoras si le parece que "un hombre vive bien si vive afligido y sufriendo" (Prt., 351b4-5), a lo cual el sofista responde negativamente. Después pregunta: “ ¿si termina su vida viviendo placenteramente, no te parece que ha vivido bien así?" (Prt., 351b6-7), y el sofista responde afirmativamente. Con base en estas respuestas, Sócrates plantea una hipótesis hedonista, según la cual "el vivir placenteramente es bueno, y con dolor malo" (Prt., 351b7-c1). Esta hipótesis luego es refinada hasta ser convertida en una formulación explícita del hedonismo, que será examinada a detalle. La hipótesis, en palabras de Protágoras, es que "se muestren como lo mismo lo placentero y lo bueno" (Prt., 351e5-6).

La consideración que el filósofo hace del hedonismo parece bastante extraña y ha suscitado una agitada controversia en décadas recientes. Parece extraño porque él emplea, en el Protágoras, esta particular concepción sobre el bien con fines argumentativos muy serios. Con base en la asunción del hedonismo, Sócrates argumenta a favor de tesis que parecen centrales no sólo para la filosofía de Platón, sino en el contexto del Protágoras: las tesis de (i) la superioridad del conocimiento sobre las pasiones y (ii) la unidad de la virtud. Pero este uso positivo del hedonismo parece ser inconsistente con la concepción platónica del hedonismo en otros diálogos, en donde se 
le rechaza claramente. ${ }^{21}$ Por ende, los especialistas han oscilado entre dos opciones interpretativas. Algunos han sostenido que, al menos en el Protágoras, Sócrates y/o Platón consideran la posibilidad de que un cierto tipo de hedonismo sea verdadero. ${ }^{22}$ Otros han sostenido que Sócrates asume el hedonismo sólo por mor del argumento, con el fin de refutar a sus interlocutores (los muchos y/o Protágoras). ${ }^{23}$ Aunque pienso que la segunda opción es la correcta, no es necesario tomar aquí una postura al respecto; pues es claro que Protágoras termina aceptando la posición hedonista que el filósofo le ofrece. Mi objetivo en este artículo es considerar la relación entre esta aceptación y el pluralismo sobre el bien de Protágoras, así como lo que esto sugiere para el examen del sofista como educador.

Protágoras se muestra reticente frente a la hipótesis planteada por Sócrates, que "el vivir placenteramente es bueno, y con dolor malo" (Prt., 351b7-c1), precisando que "si en todo caso se vive teniendo placer en las cosas nobles" (Prt., 351c1-2). Es decir, el sofista de Abdera se niega a afirmar, sin más, que todo placer es bueno. El maestro de Platón, queriendo delimitar más la opinión de su interlocutor, le pregunta: “¿o no es que también tú, como los muchos, llamas a algunas cosas placenteras malas, y a algunas dolorosas buenas?" (Prt., 351c2-3). Protágoras confirma que ésa es su posición (Prt., 351d4-7). Sócrates intenta entonces mostrar que esta postura que pretende tomar distancia del hedonismo es insostenible, para los muchos y para el sofista.

De acuerdo con Sócrates, las cosas placenteras, en tanto placenteras, son buenas, "a menos que algo distinto resulte a partir de ellas" (Prt., 351c5). Sugiere que la única razón por la cual los muchos, incluido Protágoras, sostienen que hay cosas placenteras malas y cosas dolorosas buenas radica en las consecuencias que resultan de éstas. Pero, en sentido estricto, si dejamos de lado sus consecuencias, todo lo placentero es bueno y todo lo doloroso es malo. ${ }^{24}$ Así, por ejemplo, Sócrates dice, con respecto a las cosas placenteras que a los muchos les parecen malas, que éstas no son "malas por la producción del placer mismo del momento presente, sino por las cosas que

${ }^{21}$ Cf. Grg., 495a-500a, ed. 1903; R., VI, 505b-c, ed. 2003; Phlb., 13a-c y 20c-21d, ed. Burnet 1901.

22 Por ejemplo: Divenosa, en Platón 2006, p. 201; Hackforth 1928; Irwin 1995, p. 242; Rudebusch 1989; Taylor, en Plato 1991, pp. 208-210; Vlastos 1991, pp. 300-302.

23 Por ejemplo: Grube 1933; Sesonske 1963; Sullivan 1961; Wilburn 2016; Wolfsdorf 2006, p. 133; Zeyl 1980.

${ }^{24}$ En Phlb., 12d-13d, ed. Burnet 1901, Sócrates defiende la tesis que aquí atribuye a los muchos y a Protágoras, que hay placeres malos y dolores buenos. De hecho, desde el principio sugiere en ese diálogo una concepción sobre el placer, según la cual éste es "variado"

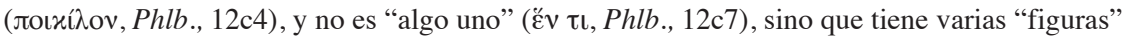
( $\mu$ o@фàs, Phlb., 12c7), posición que parece un tipo de pluralismo sobre el placer y que es, por tanto, incompatible con la posición monista que expone en el Protágoras. 
generan posteriormente" (Prt., 353d7-e1); esto es, "porque terminan en dolores y privan de otros placeres" (Prt., 353e7-354a1). De manera similar, las cosas dolorosas que los muchos consideran buenas no lo son "porque en el momento presente producen dolores y molestias extremos" (Prt., 354b1-2), sino "porque terminan en placeres, y liberación y alejamiento de las penas" (Prt., 354b6). El maestro de Platón argumenta, de este modo, que las razones que se encuentran detrás de la valoración positiva de algunos dolores, y de la valoración negativa de algunos placeres, por parte de los muchos (y Protágoras), son realmente razones hedonistas. Ciertas cosas placenteras son consideradas malas por el dolor posterior que producen, y ciertas cosas dolorosas son consideradas buenas por el placer posterior que producen.

El filósofo hace explícita esta idea central de su argumento al sostener, en tres ocasiones, que los muchos no tienen otro "fin" ( $\tau \hat{\imath} \lambda \mathrm{o}$ ) a la vista, cuando afirman que algo es bueno o malo, salvo el placer o el dolor. Por ejemplo, dirigiéndose a los muchos Sócrates pregunta: “¿o acaso pueden mencionar algún otro fin, mirando hacia el cual a estas cosas llaman buenas, sino los placeres y las penas? No podrían decir, según me parece" (Prt., 354b7-c1). ${ }^{25}$ En otras palabras, el único fin de la acción que los muchos, y Protágoras, pueden mencionar es alcanzar el placer y evitar el dolor. De esta manera, la posición sobre el bien de los muchos, incluido el sofista, es revelada como hedonista. El bien es identificado con el placer y el mal con el dolor porque los muchos, y Protágoras, no tienen otro fin o principio al cual apelar y con respecto al cual llamar a algo bueno o malo: "pero todavía incluso ahora es posible que se retracten, si de algún modo pueden decir que algo distinto es el bien que el placer, o el mal algo distinto que la molestia" (Prt., 354e8355a2). Sócrates pone, así, un énfasis especial en la idea de que es por la incapacidad de los muchos, y de Protágoras, de nombrar a un bien distinto del placer que éstos terminan comprometidos con el hedonismo. ${ }^{26}$

El hedonismo que este filósofo hace que el sofista de Abdera acepte es una especie de hedonismo particularmente extremo, que no reconoce ni siquiera la posibilidad de que algún placer no sea bueno, pues no admite ningún otro criterio o principio por el cual las cosas puedan ser buenas. Es claro, entonces, que este tipo de hedonismo es una forma de monismo sobre el bien, porque, de acuerdo con el primero, sólo hay una propiedad o forma de lo bueno: ser placentero. Este tipo de hedonismo es, así, equivalente a la negación de cualquier forma de pluralismo; el bien, en esta concepción, no es "múltiple y variado". Por tanto, este hedonismo, que Protágoras termina aceptando, es inconsistente con el pluralismo sobre el bien expresado

${ }^{25}$ Los otros dos pasajes, exactamente paralelos a éste, están en Prt., 354d1-3 y 354d7-e2.

${ }^{26}$ En Prt., 358a-c, Sócrates hace que todos, incluidos los tres sofistas Hipias, Pródico y Protágoras, acepten la tesis hedonista a favor de la cual ha argumentado. 
anteriormente por el sofista. Si esto es correcto, el discurso de Protágoras sí recibe una respuesta, sutil, pero efectiva. Sócrates muestra que el pluralismo sobre el bien es insostenible para Protágoras, ya que el sofista es incapaz de mencionar otro criterio o principio, distinto del placer, gracias al cual las cosas puedan ser buenas.

De este modo, el discurso sobre el bien desempeña un papel muy específico: es uno de los elementos necesarios para demostrar que el sofista tiene una posición inconsistente acerca del bien. Protágoras empieza formulando su posición sobre el bien, el pluralismo; sin embargo, es conducido por Sócrates a una posición monista que él parece rechazar inicialmente, el hedonismo. Esta estrategia socrática de llevar al sofista a una inconsistencia es parte importante del objetivo general de la conversación: evaluar si Protágoras es un educador apropiado, pues Sócrates muestra que su interlocutor no tiene conocimiento sobre una cuestión central para la educación: el bien. ${ }^{27}$ El sofista se ha revelado como un mero mercader de alimentos del alma, enseñanzas; pero no como un auténtico experto o conocedor de estas cuestiones, un médico del alma. ${ }^{28}$ Como vimos, el aprendizaje que Protágoras pretende enseñar es la "buena deliberación" ( $\varepsilon \dot{u} \beta o v \lambda i ́ \alpha)$, que Sócrates toma como equivalente a la técnica o virtud política. Pero, la deliberación únicamente puede ser buena si es efectiva para conseguir el bien, es decir, si es capaz de orientar la acción hacia el bien. Sin embargo, si el sofista no sabe qué es el bien, entonces la habilidad de deliberación que enseña no necesariamente es buena. Esto es, Protágoras parece capaz sólo de enseñar una habilidad discursiva y lógica que, en principio, puede ser usada para cualquier fin, bueno o malo. ${ }^{29}$ Así, sus enseñanzas podrían ser peligrosas para cualquiera que no sepa ya qué es el bien. Por tanto, no parece conveniente que Hipócrates se convierta en discípulo de dicho sofista.

${ }^{27}$ Estoy en contra de la interpretación de Wilburn 2016, pp. 229-230, quien piensa que la posición real de Protágoras es el hedonismo, pues el estudioso no se da cuenta de que el hedonismo es inconsistente con el pluralismo expresado en el discurso sobre el bien. En cambio, Wilburn parece pensar que dicho discurso anticipa de alguna manera el hedonismo que, posteriormente, Sócrates hará que Protágoras acepte: la función dramática y dialéctica del discurso es "to make room for his role as a spokesperson for the Many's hedonism in the final argument" (2016, p. 229).

${ }^{28}$ Sócrates parece sugerir irónicamente esto cuando concluye que la técnica métrica sobre el placer y el dolor es lo que enseñan los sofistas, en tanto médicos de la ignorancia (Prt., 357e), pues es claro que la posición monista sobre el bien, que está en la base de esta técnica, y la técnica misma, distan mucho de ser los aprendizajes que enseña Protágoras.

${ }^{29}$ Como vimos en la sección II, Sócrates sugiere esto también en Prt., 333d5-8. 


\section{BIBLIOGRAFÍA}

\section{Fuentes antiguas}

Plato, Protagoras, transl. and notes Christopher C. W. Taylor, Oxford, Clarendon Press, 1991 (2a. ed.).

Platón, Protágoras, intr., trad. y notas Marisa Divenosa, Buenos Aires, Losada, 2006.

Platonis Protagoras, ed. and comm. Adele M. Adam, and James Adam, Cambridge, Cambridge University Press, 1893.

Platonis Opera, t. II, ed. John Burnet, Oxford, Clarendon Press, 1901.

Platonis Opera, t. III, ed. John Burnet, Oxford, Clarendon Press, 1903.

Platonis Opera, t. I, ed. Elizabeth A. Duke et al., Oxford, Clarendon Press, 1995.

Platonis Respublica, ed. Simon R. Slings, Oxford, Clarendon Press, 2003.

\section{Fuentes modernas}

Apfel, Lauren J., The Advent of Pluralism. Diversity and Conflict in the Age of Sophocles, Oxford, Oxford University Press, 2011.

Benson, Hugh, "A Note on Eristic and the Socratic Elenchus", Journal of the History of Philosophy, 27/4, 1989, pp. 591-599, DOI: 10.1353/hph.1989.0083.

Duncan, Roger, “Courage in Plato's Protagoras", Phronesis, 23/3, 1978, pp. 216228, DOI: $10.1163 / 156852878 X 00118$.

Grube, George M. A., "The Structural Unity of the Protagoras", Classical Quarterly, 27/3-4, 1933, pp. 203-207, DOI: 10.1017/S0009838800016979.

HACKForth, Reginald, "Hedonism in Plato's Protagoras", Classical Quarterly, 22, 1928, pp. 39-42, DOI: 10.1017/S0009838800000215.

Harman, Gilbert, "Moral Relativism Defended", Philosophical Review, 84/1, 1975, pp. 3-22, DOI: $10.2307 / 2184078$.

Irwin, Terence, Plato's Ethics, Oxford, Oxford University Press, 1995.

Kerferd, George B., "Plato's Account of the Relativism of Protagoras", Durham University Journal, 42, 1949, pp. 20-26.

Kerferd, George B., "Protagoras' Doctrine of Justice and Virtue in the Protagoras of Plato", Journal of Hellenic Studies, 73, 1953, pp. 42-45, DOI: 10.2307/628234.

McCoy, Marina Berzins, "Protagoras on Human Nature, Wisdom, and the Good: The Great Speech and the Hedonism of Plato's Protagoras", Ancient Philosophy, 18/1, 1998, pp. 21-39, DOI: 10.5840/ancientphil199818110.

Moser, S., and G. L. Kustas, "A Comment on the 'Relativism' of the Protagoras", Phoenix, 20/2, 1966, pp. 111-115, DOI: 10.2307/1086051.

Roochniк, David, "Socrates' Use of the Techne-Analogy", The Journal of the History of Philosophy, 24/3, 1986, pp. 295-310, DOI: 10.1353/hph.1986.0053.

Ross, W. David, The Right and the Good, Oxford, Oxford University Press, 1930. Rowetr, Catherine, "Relativism in Plato's Protagoras", in Verity Harte and Melissa Lane (eds.), Politeia in Greek and Roman Philosophy, Cambridge, Cambridge University Press, 2013, pp. 191-211. 
Rudebusch, George, "Plato, Hedonism, and Ethical Protagoreanism", in John Anton and Anthony Preus (eds.), Essays in Ancient Greek Philosophy, vol. 3, Plato, Albany, SUNY Press, 1989, pp. 27-40.

Schiller, Ferdinand C. S, "Plato or Protagoras?", Mind, 17/4, 1908, pp. 518-526. DOI: $10.1093 / \mathrm{mind} / \mathrm{XVII} .4 .518$.

Sesonske, Alexander, "Hedonism in the Protagoras", Journal of the History of Philosophy, 1/1, 1963, pp. 73-79, DOI: 10.1353/hph.2008.1475.

Sullivan, J. P., “The Hedonism in Plato's Protagoras", Phronesis, 6/1-2, 1961, pp. 10-28, DOI: 10.1163/156852861X00026.

TAYlor, Alfred E., Plato: The Man and His Work, London, Methuen, 1927.

Thomson, Judith Jarvis, "The Right and the Good", Journal of Philosophy, 94/6, 1997, pp. 273-298, DOI: 10.2307/2564542.

Versenyi, Laszlo, "Protagoras' Man-Measure Fragment", American Journal of Philology, 83/2, 1962, pp. 178-184, DOI: 10.2307/292215.

Vlastos, Gregory, "Introduction", in Benjamin Jowett (transl.), Martin Ostwald (rev.), Plato. Protagoras, New York, The Liberal Art Press, 1956, pp. vii-lviii.

Vlastos, Gregory, "The Socratic Elenchus", Oxford Studies in Ancient Philosophy, 1, 1983, pp. 27-58.

Vlastos, Gregory, Socrates. Ironist and Moral Philosopher, Ithaca, Cornell University Press, 1991.

Wilburn, Josh, "Plato's Protagoras the Hedonist", Classical Philology, 111/3, 2016, pp. 224-244, DOI: 10.1086/687099.

Wolfsdorf, David, "The Ridiculousness of Being Overcome by Pleasure: Protagoras 352B1-358D4", Oxford Studies in Ancient Philosophy, 31, 2006, pp. 113-136.

Wright, Crispin, "Relativism about Truth Itself: Haphazard Thoughts about the Very Idea", in Manuel García-Carpintero and Max Kölbel (eds.), Relative Truth, Oxford, Oxford University Press, 2008, pp. 157-186.

ZeYL, Donald J., "Socrates and Hedonism: Protagoras 351b-358d”, Phronesis, 25/3, 1980, pp. 250-269, DOI: 10.1163/156852880X00151.

$$
* * *
$$

José Edgar González Varela es doctor en Filosofía por la Universidad de Sheffield, Reino Unido. Se desempeña como investigador en el Instituto de Investigaciones Filosóficas de la Universidad Nacional Autónoma de México. Su área de especialización es la historia de la filosofía antigua, en particular la metafísica de Platón y Aristóteles. Ha publicado artículos sobre estos temas en revistas especializadas nacionales e internacionales como Apeiron, Diánoia, Nova Tellus, Phronesis y Revista Latinoamericana de Filosofía. 